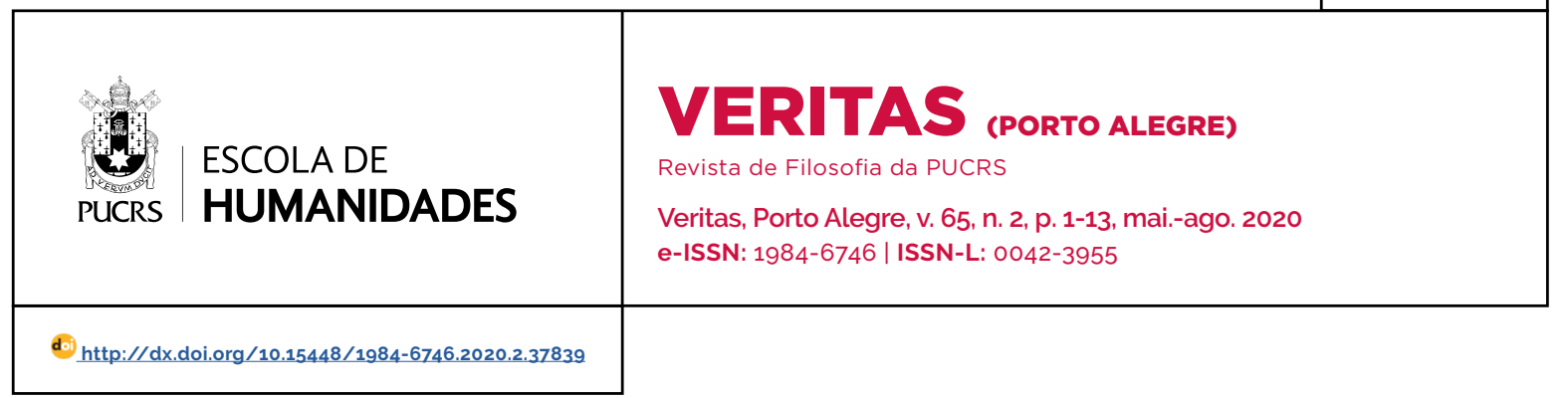

SEÇÃO: ESTÉTICA

\title{
El desierto era parecido a un paraíso. Aventuras posthumanas en una novela de G. Cabezón Cámara
}

\author{
O deserto era parecido a um paraiso. Aventuras pós-humanas em uma novela de G. \\ Cabezón Cámara
}

The desert felt like a paradise. Posthuman adventures in a novel by G. Cabezón Cámara

\section{Paula Fleisner ${ }^{1}$ \\ orcid.org/0000-0003-0157-2476 \\ pfleisner@gmail.com}

Recebido em: 06 mai. 2020

Aprovado em: 17 mai. 2020.

Publicado em: 28 jul. 2020.
Resumen: Este artículo parte de la perspectiva del materialismo posthumano, una línea de investigación que asume el presente como un contexto postantropocéntrico y postnatural en el que se ha vuelto indispensable volver a considerar las diversas lógicas de existencia que pueblan la Tierra. Es decir, se trata de pensar el espacio post/inhumano que se abre con la interacción, la hibridación y la co-emergencia de todo lo existente en la que los actores humanos están presentes pero no ya en el centro de la acción, sino en una mezcla de agencialidades diversas. En esta oportunidad se presentará una lectura de Las aventuras de la China Iron, de Gabriela Cabezón Cámara (2017), desde una estética materialista posthumana. Por un lado, en la medida en que la narradora es un animal humano, la novela será entendida como una descripción horizontal y no jerárquica del lugar de la "humanidad" en el planeta; $y$, por el otro, como la exploración de las mutuamente contaminadas potencias de actuar, pensar y sentir de lo existente en general: lo animal, lo vegetal y lo mineral no ya taxonomizados en reinos sino mezclados en el "compost" sin alambrado, ingobernable y fértil que podria ser el "desierto" argentino. De esta forma, en tanto que reescritura del Martín Fierro, texto considerado fundacional de la identidad nacional argentina, la novela de Cabezón Cámara podria ser la fabulación de una "matria" queer y holoéntica que alberga criaturas de múltiples especies y reinos.

Palabras clave: materialismo- posthumanismo- literatura argentina- desierto.

Resumo: Este artigo parte da perspectiva do materialismo pós-humano, uma linha de pesquisa que assume o presente como um contexto pós-antropocêntrico e pós-natural no qual se tornou indispensável reconsiderar as diversas lógicas de existência que povoam a Terra. Ou seja, trata-se de pensar sobre o espaço pós/desumano que se abre com a interação, a hibridização e a co-surgimento de todo o existente em que atores humanos estão presentes, mas não mais no centro da ação, senão em uma mistura de agencialidades diversificadas. En esta oportunidad será apresentada uma leitura de Las aventuras de la China Iron, de Gabriela Cabezón Cámara (2017), a partir de uma estética materialista pós-humana. Por um lado, na medida em que o narrador é um animal humano, o romance será entendido como uma descrição horizontal e não hierárquica do lugar da "humanidade" no planeta; e, por outro lado, como a exploração das mutuamente potencias de agir, pensar e sentir do existente em geral: o animal, o vegetal e o mineral não mais taxonomizados em reinos, senão que misturados no "compost" intransigivel, ingovernável e fértil que poderia ser o "deserto" argentino. Assim, como reescrita de Martín Fierro, um texto considerado fundacional da identidade nacional argentina, o romance de Cabezón Cámara poderia ser a fabulação de uma "matria" queer e holoentica que abriga criaturas de múltiplas espécies e reinos. Palavras-chave: materialismo- pós-humanismo- literatura argentina- deserto.

Abstract: In this paper we provide a reading of Gabriela Cabezón Cámara's Las aventuras de la China Iron (2017) from a post-human materialistic aesthetic perspective, a line of research which considers that, in our post-anthropocentric and post-natural context, it has become essential to revisit the various logics 
of existence that populate the Earth. In other words, we attempt to think about the post/in-human space that opens up with the interaction, hybridization and co-emergence of everything that exists, a space in which human actors are present but instead of being the center of action inhabit a mix of diverse agencies. From this particular point of view we focus on two issues. Insofar as the narrator is a human animal, on the one hand the novel is understood as a horizontal and non-hierarchical description of the place of "humanity" on the planet, on the other hand, as the exploration of mutually contaminated powers of acting, thinking and feeling of what exists in general. According to this, the animal, the vegetable, and the mineral are no longer taxonomized in kingdoms but mixed in the unwired, ungovernable and fertile "compost" that the Argentinian "desert" could be. Considered as a rewriting of Martin Fierro, a foundational book of Argentina's national identity, Cabezón Cámara's novel can be read as the fable of a queer and holoentic "matria" that is the home to multiple species and kingdoms creatures.

Keywords: materialism- posthumanism- Argentinian literature- desert.

A Gabriela Cabezón Cámara, hada madrina

\section{Coordenadas para un materialismo estético poshumano}

Este trabajo forma parte de una investigación en torno al materialismo posthumano comprendido no como una nueva teoría en disputa por un lugar en la agenda del pensamiento contemporáneo sino como una caja de herramientas conceptuales siempre abierta y en revisión. Se trata de un marco teórico a partir del cual generar ideas, narraciones y prácticas que permitan pensar la paradójica situación en la que nos encontramos y a la cual podríamos llamar postantropocentrismo antropocénico. Es decir, el curioso momento en el que simultáneamente, por un lado, el "sujeto" (humano) ha dejado de ser el centro de gravedad de las prácticas y los discursos capitalistas que rigen los destinos del mundo dejándole lugar a la materia en su conjunto como objeto de apropiación (cfr. Braidotti, 2015); y, por otro lado, la "humanidad", en su búsqueda de dominio total de la "Naturaleza" ha transformado el planeta de forma irreversible, deviniendo asi ella misma una fuerza geológica (Stengers, 2017,). Un momento raro que (hoy más que nunca, con una pandemia global que detuvo forzosamente la marcha habitual del tiempo y el espacio) podria ser el kairós, la ocasión para poner en tela de juicio in toto el sistema de producción (Latour, 2020) que nos trajo hasta aqui y para sustraernos de aquello que hasta ahora el realismo capitalista nos presentaba como irrefrenable (Fischer, 2016). De alli tal vez, la importancia de volver a la tarea que Foucault (1996) proponía a la filosofia: hacer una ontologia del presente, que, en nuestro caso debería reconsiderar a partir del descentramiento de lo humano las capacidades de actuación, pensamiento, sensibilidad y emotividad implicadas en otras formas de existencias, vivas o no, a partir de un concepto de materia que ya no sea el correlato inerte y disponible de un espiritu que la domina y le da forma.

A partir de la puesta en diálogo de tradiciones diversas, el materialismo posthumano se ubica, de este modo, dentro de las filosofias posteriores al "giro materialista" y se sabe heredero de aquellos antihumanismos del siglo $X X$ que pusieron en evidencia la relación necesaria entre la erección de un ego (humano, varón, individual, ciudadano, blanco, burgués, habitante de una comunidad y hablante de un idioma globalmente reconocidos) y la justificación del dominio extractivista no sólo sobre el resto de la humanidad sino también sobre todo lo existente en el planeta (y, eventualmente, sobre toda otra superficie conquistada o conquistable fuera de él).

La disputa del materialismo no es nueva. Ya en el siglo pasado Adorno advertía con claridad qué se pone en juego en ella: se trata ni más ni menos que de desandar el "egoismo" del idealismo entendido como filosofía que deriva toda la realidad del principio del "yo", al ser el sujeto quien funda el conocimiento $y$ al ser éste quien funda la realidad (Adorno, 1977, §22). Por ello el materialismo deberá desenmascarar el espíritu como principio de dominación de lo relegado al no-yo y partir de la experiencia corpórea del placer y del displacer como momento no cognitivo que atraviesa incluso la espiritualidad. El materialismo, como ya pedía a gritos el propio Nietzsche, desconfia de lo noble, lo eterno y lo imperecedero y es, antes que un conjunto doctrinario preciso, un "aroma", una coloración 
que recuerda cualidades fisiológicas sensitivas surgidas de los cuerpos (Adorno, 1977, § 33).

De entre todas las reversiones contemporáneas del materialismo, es quizás el feminismo materialista la versión que pensó mejor la necesaria vinculación entre el materialismo y el posthumanismo: luego de la etapa deconstructiva de las implicancias del concepto de género, hubo dentro de ciertos feminismos un retorno a las prácticas y experiencias corporales (Rossini, 2006, 2) que los ha llevado a proponer una revuelta emancipatoria general alejada de la lógica reivindicatoria de la inclusión de ciertos sectores antes excluidos dentro del círculo de "vidas que importan". Una revuelta no humanista, ni antrópica ni andrópica, que asume la inmersión de lo existente en una red de relaciones no-humanas (animales, vegetales, virales o minerales) ante el cual es necesario ser capaz de dar respuesta: un respons-able devenir-con, para decirlo con las filósofas más célebres del feminismo materialista (cfr. Braidotti, 2017, 21-27; Rossini, 2006, 17y Haraway, 2019, 32).

Partiendo de estas coordenadas, también la Estética puede producir discursos no antrópicos que impliquen una rehabilitación política de la aisthesis. Nacida en la modernidad como disciplina filosófica que auxilia a sus hermanas "mayores" (la Gnoseología y la Ética) en la tarea de entronizar y garantizar la soberanía de la nueva figura conceptual, el sujeto, la Estética, podria no obstante, colaborar en la tarea la construcción de un "materialismo sensible" a partir del cual imaginar una redistribución de la potencia de sentir (percibir y ser afectado) y de la potencia de actuar. Lo cual le permitiría además conceptualizar la capacidad que siempre tuvo el arte tanto para testimoniar por los modos de vida y de existencia olvidadas o exterminadas, como para fantasear formas nuevas de existencia simpoiéticas -lo que Haraway llama "fabulaciones especulativas" que escapen a la falsa dicotomía entre apocalipsis y salvación y se mantengan unidas a la política confabulando modos colectivos de devenir-con, parentescos raros (Haraway, 2019, 228-229).

La paradójica situación en la que nos encontramos, a la que me permití nombrar, no sin rim- bombancia, postantropocentrismo antropocénico, es sobre todo un fenómeno sensorial, que por lo demás, todxs percibimos: tenemos la experiencia diaria de la construcción de un mundo tóxico y disminuido (Davis- Turpin, 2015, 3) a la vez que también observamos cómo no somos el objeto privilegiado de la explotación, sino que todo lo que hay ha devenido recurso disponible y explotable, dado que la economía global tiene una estructura tecno-científica sostenida por una mercantilización de la materia viva y no viva. Es por ello que, en tanto ocupada con nuestra aisthesis, la Estética podría ser la disciplina filosófica que mejor colabore con la comprensión de esta situación y con la revuelta no ya sólo humana de las cosas. Si en el proceso de dominio total hemos sustraido a los demás modos de existencia la percepción, la sensación, el sentir, el pensar, el actuar y hasta el ser (por tratarse de formas específicas y extrañas a la humana) la Estética puede conceptualizar tanto esas formas como los modos en los que el arte fantasea el estar abierto en relaciones múltiples de los diversos modos simpoiéticos que habitan el planeta. La Estética puede ser la gran aliada del llamado a la revuelta, a la re-imaginación de las relaciones dinámicas y contingentes entre lo biótico y lo abiótico. Y puede, entonces, conceptualizar y analizar aquellas manifestaciones artísticas que juegan con la interconexión de la materia en otros tiempos y espacios posibles, cuestionando incluso las relaciones jerárquicas y estancas entre lo orgánico y lo inorgánico o los territorios en los que esas divisiones se hacen posibles. Un arte que, para decirlo con Agamben, asume y soporta en su gesto la pura medialidad (Agamben, 2001, 68) de lo que hay, exhibiendo y fantaseando siombiogénesis y holoentes de toda clase (cfr. Haraway, 2017, 25-50).

En lo que sigue presentaré una lectura de Las aventuras de la China Iron, de Gabriela Cabezón Cámara (2017), desde una estética materialista posthumana. Por un lado, en la medida en que la narradora es un animal humano, la novela será entendida como una descripción horizontal y no jerárquica del lugar de la "humanidad" en el planeta; y, por el otro, dado que la narración 
desborda el punto de vista humano, se analizará la exploración que ella propone de las mutuamente contaminadas potencias de actuar, pensar y sentir de lo existente en general: lo animal, lo vegetal y lo mineral ya no taxonomizados en reinos sino mezclados en el "compost" sin alambrado, ingobernable y fértil que podría ser el "desierto" argentino. De esta forma, en tanto que reescritura del Martín Fierro, texto considerado la gran "epopeya" argentina, la novela de Cabezón Cámara podría ser, y en contraste con él, la fabulación de una "matria" queer y holoéntica que alberga criaturas de múltiples especies y reinos.

\section{Parodia magnifica: flor de cactus en el desierto}

La novela ofrece un ejercicio de escritura que, como las historias que narran los habitantes de la Terrápolis imaginada por Haraway (2019, 32-33), no parte de la nada sino que se ubica ni más ni menos que en la estela de la narración que ha forjado los valores de la identidad nacional argentina, el poema gauchesco de José Hernández², para iluminar desde ahí el mundo dañado que ha quedado olvidado en aquella descripción del prototipo de gaucho heroico y sacrificado, pícaro y entrañable. Cuenta la partida de la China Iron que, en un juego tergiversante de conservación y transformación del sentido del apellido de su marido, Fierro, se autodenomina del modo más impersonal posible: se da a sí misma el nombre genérico con el que los gauchos denominaban a sus esposas, "china" (del quechua: "muchacha"). Una partida después de una partida: se imagina lo que sucede con este personaje luego de que su marido la dejara junto a sus dos hijos al ser llevado por "el coronel" Hernández.

Leemos aquí, entonces, un contar que no es "desde cero". Incluso aunque comienza en el "desierto", ese gran tema literario que desveló a los escritores argentinos, éste no es un comienzo desde cero. Incluso aunque en la literatura argentina el desierto haya funcionado como "el laboratorio onírico" de imágenes virtuales de una extraña "ausencia de paisaje", ausencia que a su vez funciona como metáfora de otra ausencia: la ausencia de política que evoca "la plenitud ausente de un estado-nación por venir", de acuerdo a la reconstrucción que ofrece Rodriguez en Un desierto para la nación $(2010,15)$. Aquí el desierto no es una ausencia. La novela se ocupa de desmontar las capas de ese pretendido espacio vacio, de esa falsa tabula rasa lograda en todo caso a fuerza de exterminio, para señalar en dirección de todos los seres insignificantes que en realidad la pueblan. $Y$ es que en esta novela no sólo se dan cita las figuras humanas que aparecen en todos los relatos del desierto y que bien podrian haber alertado contra la proclama del vacio (los "jinetes, nómadas, indios, gauchos solitarios, partidas de soldados, desertores, arrieros, caravanas de carretas, viajeros criollos y europeos, pulperos, estancieros y peones", mencionados por Rodríguez), sino también perros, vacas, polvo, caranchos, huesos, y, más tarde, ya en tierra adentro, rios, pastizales, ombúes, pájaros azules y más. Por ello aqui el desierto no es la nada, es, como veremos, una vasta compostura, que pone juntas entidades de toda calaña. $Y$ no es desde cero, a su vez, porque la novela tiene un modelo serio con el que establece una relación paródica, es decir, un vínculo que busca mostrar la escisión entre las palabras y el mundo que en su modelo se mostraban unidos, en este caso, además, para sostener un relato identitario fundacional. Como recuerda Agamben a propósito de L'isola di Arturo de Elsa Morante, la parodia como género literario es la irrupción, el pará-oiden, el ponerse al lado

\footnotetext{
2 Poema narrativo en verso escrito por José Hernández que narra la historia del gaucho Martín Fierro, un habitante de la pampa húmeda que es reclutado de forma compulsiva para formar parte de las milicias que custodian los fortines que sirven de fronteras internas contra los indigenas a fines del siglo XIX. Narra, de esta forma, el devenir "matrero" (sin ley) de este gaucho inicialmente trabajador y abnegado por causa de un sistema social que el autor denuncia como injusto. Se trata en realidad de dos relatos, conocidos con el nombre integral de Martin Fierro, pero escritos con siete años de diferencia entre ellos: El gaucho Martín Fierro, de 1972, conocido como "La ida", y La vuelta de Martín Fierro, de 1879. Referencia obligada de la literatura gauchesca argentina, este poema ha sido considerado el inventor de la figura del gaucho como emblema de la argentinidad. No llevaré a cabo aqui un análisis pormenorizado de la relación de la novela de Cabezón Cámara con este libro, pues me interesa pensar sus posibles conexiones con el materialismo posthumano sin entrar en las discusiones expertas sobre la literatura gauchesca, pero en lo que respecta al lugar del Martín Fierro en la construcción de la patria argentina remito al insoslayable libro de Ludmer (2012) y a los análisis herederos de éste que propone Gamerro (2015).
} 
de los relatos rapsódicos serios para trasponer el sentido hacia lo ridículo o cómico (Agamben, 2005, 40-41). La China es, entonces, el relato de un "como si no" hubiera acontecido la fundación de la identidad de la patria martinfierrera y se sostiene en el umbral donde se hace evidente la imposibilidad de coincidencia entre el lenguaje y el mundo; desfasaje, fuera de quicio que, eventualmente, podría dar lugar a la de-fundación de la nación andrópica hecha de gauchos valientes y vivos ${ }^{3}$.

Hay en la novela un juego narrativo, frecuente en la literatura contemporánea, que consiste en hacer hablar a los personajes que han quedado sin voz en textos clásicos, para denunciar sus aspectos hegemonizantes "naturalizados": como la reconstrucción de la vida del árabe anónimo asesinado en El Extranjero en boca de su hermano en la novela de Kamel Daoud; o como el relato de Bertha Antonietta Masson convertida en la "mujer loca del ático" de Jane Eyre que nos presenta Jean Rhys ${ }^{4}$, la China Iron narra su historia no para reconciliarse ni para restaurar un orden perdido sino para dar cuenta de otros modos posibles de existencia silenciados también en la construcción de cánones literarios.

El texto está dividido en tres partes ("El desierto", "El Fortín" y "Tierra adentro") y relata un viaje que parte de la sujeción subjetiva en la que se encuentra el personaje que narra, la china, para arribar a la constitución de una comunidad interreinos tierra adentro, pasando por la construcción inicial de un vistoso conjunto multi-especifico en el desierto y por la deconstrucción del proyecto civilizatorio argentino en el fortín. Veamos en detalle cómo acontece.

\section{Señora de nadie (nada, nunca). Muchacha indecible}

Vivir la vida como una iniciación. Pero ¿a qué cosa? No a una doctrina, sino a la vida misma y a su ausencia de misterio. Esto hemos aprendido, que no hay ningún misterio, sólo una muchacha indecible.

G. Agamben, La ragazza indicibile Según una definición más o menos canónica, una Bildungsroman se inicia con una pérdida emocional en la infancia o primera juventud que da lugar a un viaje que a su vez servirá para encontrar una respuesta frente a los interrogantes a los que fue arrojado el protagonista. Esta respuesta ayudará a que se adapte al mundo y logre, en su madurez, una relación fluida y provechosa con la sociedad 5 .

A primera vista, podria considerarse que Las aventuras de la China Iron es una reformulación de este género literario, pues pareciera respetar la estructura tripartita de Jugendlehere (aprendizaje de juventud que queda narrado casi con la misma displicencia con que el personaje es tratado en el Martín Fierro donde nació), Wanderjahere (peregrinación que ocuparia la totalidad de la novela) y Läuterung (el perfeccionamiento que podria estar encarnado aqui por el final en fade out). Sin embargo, se trata en todo caso de una especie de détournement (o de parodia, como deciamos más arriba) del género, pues no se asume con dolor anímico el pasado de opresión: "parida por los yuyos", criada por la Negra maltratadora, entregada al gaucho como premio en una partida de truco y ya con dos hijos a la edad de catorce años $(12-13)^{6}$, todo esto lo cuenta la China casi al pasar. Y tampoco la "pérdida" de

\footnotetext{
3 Una de las características exaltadas en el Martín Fierro es la de la así llamada "viveza criolla" expresada en sentencias como "hecha la ley hecha la trampa", una especie de astucia acomodaticia pero no necesariamente vil o malvada, que ubica al gaucho por fuera de la dicotomia "ley/no-ley". Para un análisis de la cuestión remito a Gamerro, 2015, 83-85 y a las últimas páginas del libro de Ludmer, 2012,302 y stes. 4 En la novela de Kamel Daoub, Mersault, contre-enquête (2013), el narrador cuenta la historia de su hermano Moussa Assasse, el árabe sin nombre, muerto en L'Étranger (1942) de Albert Camus. En la de Jean Rhys, Wide Sargasso See (1966) se cuenta la historia de Bertha, la "blanca mestiza" del Caribe que se transforma en esposa del cazafortunas Mr. Rochester y termina encerrada en el ático, de quien tampoco sabemos nada en el relato de Charlotte Brontê (1847). Podría decirse que en ambos casos se trata de ejercicios "decoloniales" donde lxs escritores, el primero argelino la segunda dominiquesa, buscan saldar cuentas con el acriticismo colonializante de la erección de los grandes clásicos literarios. La novela de Cabezón Cámara pareciera dar un paso ulterior, lúdico y paródico, incorporando elementos ya no sólo humanos en su historia de lo que quedó fuera del relato fundacional de la patria argentina: se trata no ya de una denuncia de la exclusión de modos de vida humanos que deberian ser incluidos en la economía de los derechos a pertenecer a la polis, sino del señalamiento del extractivismo generalizado implicado en la construcción de la nación en el desierto a la vez que de la recuperación siempre parcial de las formas de existencia y modos del entendimiento implicadas en todo el proceso. Lejos de ser una reivindicación de un origen pristino al que habría que volver o restaurar, es la fabulación de un espacio-tiempo ya no natural ni cultural abierto en la contaminación continua de todo lo que hay.

5 No es el objetivo de este trabajo entrar en las innumerables polémicas en torno a este género literario ni analizar las implicancias filosóficas que han derivado de él. Para un análisis ya clásico remito al texto de F. Moretti (2000).

6 Cito entre paréntesis las páginas de la novela en la edición mencionada en la Bibliografía, y usaré como abreviatura del nombre de la novela La China.
} 
Fierro (su marido reclutado) es verdaderamente una pérdida emocional, sino que es vivida como una oportunidad para la libertad. Y si bien se inicia aqui un viaje, éste no es guiado por una finalidad, una pregunta existencial o una búsqueda de comprensión del mundo con el objetivo de una mejor adaptación a él. Se trata de una travesía, como analizaré más adelante, hacia la aventura plural del devenir con existentes asociados y no hacia la constitución de una individualidad humana. Finalmente, tampoco hay una instancia de reconciliación con la sociedad de la que se partió, sino que asistimos quizás a la invención de una nueva forma de comunidad.

Si, como se ha definido desde el materialismo ecocultural, el Bildungsroman es la radical afirmación de la excepcionalidad humana en la medida en que narra la historia de un individuo a partir del mito humanista de su separación y oposición respecto de la naturaleza (Feder, 2014, 2-3) ${ }^{7}$. Las aventuras de la China Iron es, entonces, una especie de Unbildunsroman, una novela de de-formación, que narra el desprenderse de los pocos rasgos individualizadores, el progresivo desajuste de la oposición naturaleza/cultura cuya validez estructurante de las subjetividades modernas queda desbaratada al final. Asi, esta deformación es también una barbarización, una bestialización, es decir, la inestabilización del binomio hombre/ animal sin que implique la "elección" entre uno de ellos: como Cioran ante el dilema hamletiano, nuestra china parece decirnos, burlona: "ni lo uno ni lo otro". Aqui se cuenta un tránsito cronológico de la niñez a la adultez que no es una descripción de un crecimiento físico, moral, psicológico y social, sino que es la narración de un escape no sólo de la sujeción de la individualidad, del encierro en una "identidad personal" humana (mujer, joven, blanca, esposa, madre, pobre) sino también un escape de la excepcionalidad misma de la especie humana, hacia la invención de una comunidad del amor terráqueo.
Sin embargo, hay algo que, después de todo, quizás si comparte con el que ha sido considerado prototipo de la novela de formación, Los años de aprendizaje de Wilhem Meister (1796/96) de Goethe, al menos en la lectura que propone Max Kommerell y que Agamben retoma para pensar el "gesto". Según Kommerell, en el relato de Goethe se produce una iniciación mundana a la vida misma sin recurrencia a una enseñanza o una doctrina, sin apelaciones a instancias trascendentales (el Estado, la sociedad, la Iglesia) que pudieran otorgar un sentido sagrado por fuera de la contingencia terrenal en la que la vida puede, al fin, comenzar: "[...] a la vida le ha sido confiada aquí una potencia que habitualmente sólo era ejercitada dentro de esferas sagradas", ella es la iniciadora, pero ... "¿Y a qué inicia? No a su sentido, sólo a sí misma", afirma el crítico alemán, señalando a su vez que en esa iniciación la vida permanece innombrable como "un misterio de lo cotidiano y de lo mundano, que es posesión [del] poeta" (Kommerell en Agamben, 1991, XIV$-X V$ ). Esta lectura, que tensiona los elementos narrativos para pensar en el texto goetheano no una teleología que lleve más allá sino el "misterio profano cuyo único objeto es la existencia misma" (Agamben, 1991, XVI), no es incompatible con la experiencia de la intimidad del vivir aquí y ahora presentada en la novela de Cabezón Cámara, donde pareciera acontecer también una iniciación a la ausencia de misterio.

La china que cuenta esta historia se parece a aquella muchacha indecible, la Kore griega de la que nos hablan los mitólogos, que desbarata todas las determinaciones de género y de especie: es ella misma "la vida en cuanto no se deja decir o definir según la edad, la identidad sexual - las máscaras familiares y sociales" (Agamben, 2010, 12). Kore representa en los mitos eleusinos tanto a Demeter (la madre) como a Perséfone (la virgen) y es tan indeterminada que quiebra el umbral de los géneros. Según la definición

\footnotetext{
Feder habla de algunas excepciones dentro del género, donde encuentra el reconocimiento de una agencialidad no humana y de algo así como una subjetividad. Aunque Feder no trabaja con el texto de Goethe, acaso siguiendo sus sugerencias podria pensar en el Wilhem Meister, a partir de la lectura de Kommerell, como un texto disruptivo respecto de la propia constitución de la figura humana dentro de la novela. En la medida en que se trata de la reivindicación de la auto-iniciación de la vida inmanente producida en la literatura, no se trataría de la consecución de una "forma simbólica".
} 
etimológica, es la fuerza vital, el impulso que crece y hace crecer plantas y animales (Agamben, 2010, 9). Ese principio es el que parece encarnar la China nacida de los pastitos de flores violetas (12) cuyo nombre de hembra impersonal se va (in)determinando genéricamente: primero es Josephine, en homenaje a la crítica literaria que explicitó la lógica dual de la gauchesca8; luego es un muchacho, y con el corte de su larga trenza viene también la masculinización por acortamiento de su nombre; pero su indeterminación no es sólo genérica, también es especifica, pues, tanto al adoptar el apellido Star en honor a su perro Estreya como cuando empieza a llamarse Tararira, asume ella su procedencia animal; asi como transgrede también la diferenciación de reinos al decidir conservar su apellido de casada, Fierro, en un doble proceso de traducción/traición como Iron, haciendo propia una pertenencia mineral inatrapable ya en las falsas dicotomias entre lo vivo y lo no vivo.

De esta forma, la novela refiere el curioso devenir de la esposa-madre-niña a la que el gaucho Martín Fierro dejó allá en el caserio con sus dos hijos cuando fue arriado (como las vacas, porque, en definitiva, ¿cuál es la diferencia entre un gaucho y el ganado de otros que custodia?) por el coronel Hernández para su estancia (160). Pero a su vez, Cabezón Cámara pareciera fantasear una salida queer y posthumana a la disyuntiva borgeana sobre la construcción de una identidad nacional a partir de un modelo literario: nuevamente, frente a las falsas oposiciones, la China menea graciosamente su dedito índice mientras nos dice "ni Martín Fierro, ni Facundo"9. Ella permanece ajena al duelo entre José Hernández (estanciero defensor de la ley de vagos que permite disponer de cuerpos útiles para el trabajo de campo) y Domingo F. Sarmiento (estadista impulsor de la ley de levas que recluta cuerpos para custodiar los fortines), figuras a las que la novela parece adrede presentar indistinguidas en el coronel-estanciero Hernández dueño de la estancia-fortín. ¿Cómo podría haber sido la invención de una nación no andrópica ni antrópica? Esta es la pregunta que parece responder nuestra novela de de-formación.

En lo que sigue propongo un pequeño ejercicio de reflexión filosófica acerca de las tres partes de la novela, reflexión que, teniendo en cuenta la crítica literaria pero sin entrar puntualmente en sus discusiones, buscará, como diría Agamben, tocar en la novela, el punto limite de su discurso: su "materia" irreductible (Agamben, 2002, 15). La literatura, como una para-ontología que parodia las relaciones univocas entre las palabras y las cosas, muestra la imposibilidad de su coincidencia (Agamben, 2005, 54). Al hacerlo, descalabra las certezas filosóficas y celebra una existencia feliz, precaria e in-fantil que se auto-inicia. Por ello, intentaré explorar aqui los modos en que la China desafia a la filosofia y le ofrece nuevos modos de concebir lo existente y sus vínculos.

\section{El desierto, continuidad de lo que vive}

La China es la muchacha indecible que mencionaba al comienzo, pura indeterminación de los lugares comunes de la feminidad (en ella, madre y virgen, mujer y niña se solapan en una indistinción vertiginosa), es también pura inestabilidad sexual (pasa de "china a lady y de lady a young gentleman" [99] y de alli a tararira [154]) y puro principio vital que hace crecer todo a su alrededor, también los humanos que la acompañan se indeterminan, se hacen otros (74). Por su parte Liz, la inglesa que la acoge en su carreta y se encarga de su educación sentimental, desestabiliza la quietud de la figura de la gringa miedosa y modosita que teme volverse una cautiva si atraviesa las fronteras del mundo bárbaro: ella es una mujer autónoma y pragmática que toma las decisiones por el conjunto heterogéneo (bueyes, china, gaucho, perro, caballos, vacas) que va reuniendo a su alrededor, estampa de un matriarcado errante que desanda con sutileza incluso ciertas lógicas colonizantes. Rosario, el gaucho semi-indio que se les une con

\footnotetext{
8 Me refiero a Josefina Ludmer y a su influyente libro El género gauchesco. Un tratado sobre la patria, donde se propone pensar las dos caras del uso del gaucho, el uso literario de su voz y el uso económico o militar de su cuerpo (Ludmer, 2012).

9 Sobre la disyunción propuesta para pensar los destinos posibles y real de la nación argentina, cfr. Gamerro, 2015- 11-17.
} 
sus mil vacas cimarronas y su corderito huérfano, Braulio, es un gaucho tierno que materna animales guachos (una liebre, un cuis y un potrillo) y pide perdón a otras madres cuando les mata sus terneros (45). Nadie está llamado aquí a cumplir con su papel en la férrea galería de personajes posibles de la Argentina en ciernes.

Pero la muchacha indecible es también "el umbral que divide y une al animal con el humano y al humano con su animalidad", porque aquí, como entre los griegos, no hay una "esfera de lo propiamente humano" (Agamben, 2010, 28-29); en esta novela no hay sujetos, individuos que descubran su identidad interior en las peripecias de un afuera, ni siquiera en la estancia-fortín de Hernández (a la que llegan en la segunda parte), que está llena de animales humanos.

El relato se abre con el encuentro de la China con Estreya, el brillo de la existencia en medio de un polvo opaco que todo lo cubre, un cachorro de ojos amarillos "que irradiaba alegría de estar vivo" (11). Sin embargo, lejos de que su aparición suture el montaje de la historia en tanto que accesorio metafórico del desamparo y la soledad de la china, este perro es quizás la puerta de entrada para que la indeterminación se traslade en el desierto a lo viviente infinito (60) que lo habita sobre y debajo de la tierra. Estreya no es la infaltable mascota colaboracionista con la constitución de un yo, sino que es, quizás, el punto de fuga inicial gracias al cual la novela se transforma en la descripción de un viaje a través de un entorno sin centros ni jerarquias, un pais de aventuras vegetales (56) en el que, sin embargo, "todo lo que vive vive de la muerte de otro o de otra cosa" (52), exposición de una lógica sacrificial sobre la que se erige la nación carnivora, e invención de vínculos solidarios de cercanía material y opacidad espiritual. El perro con sus bailecitos felices y su ausencia de ideas es el heraldo de la comunidad por venir y el guardián voluntario frente a los peligros que puedan amenazarla. De este modo, el relato va arriando y amontonando en torno a la carreta un zoo(i)lógico de animales ya no reducidos a las habituales funciones edipicas, instrumentales o fantasmales (Braidotti, 2013, 86): bueyes con pestañas curvadas de amor (139), vacas con ojos buenos como agujeros negros "hechos de ganas de pasto" (44), vacas que lloran la masacre de sus vástagos (45), caballos amados convencidos a fuerza de palabras y abrazos (70), flamencos y ñandúes, cuises y chimangos, insectos de toda clase, mariposas y caranchos, mulitas y gusanos que le nacen a la carne muerta (35), dragones y tigres, cebras e hipopótamos dibujados por Liz en su escuela ambulante (35-35). Ninguno de ellos es un Otro que define lo Uno humano que es la china, sino que es la china la que funciona como lo mismo-otro abismante respecto de ese entorno animal: ningún animal es versión de ella, en todo caso, y al final, es ella quien se vuelve versión de tararira, materia narrada en su travestismo animal, gracias a la intervención de los hongos y de la machi del pueblo de los Iñchiñ o Ñande $(154)^{10}$. Un conjunto con miedo se desplaza por el desierto, sí, pero es un conjunto unido en el amor que "se les consolidaba ante la percepción de la precariedad que somos" (83). Una mezcla de especies extrañas unidas en la fragilidad de un tiempo kairológico en el que cada momento es el riesgo de una oportunidad imprevista. Un amor de seres extraños en cuya intimidad se vive, pero cuya lejania se mantiene (Agamben, 2002, 41).

El principio de indeterminación que sostiene y moviliza la novela, no se detiene en la inclusión de los animales no humanos, pues no se busca ampliar los límites del círculo del excepcionalismo inmunitario hacia un "otro" más cercano. Por el contrario, asistimos en ella a un in crescendo de agencialidad del entorno vegetal y mineral que va formando los parentescos de una post-humanidad que se presenta simplemente como el compost, el barro primordial en el que todo está mezclado. En esa quietud que es la naturaleza de la pampa, el país se muestra como "ese humus que es materia y continente, que es matriz más que ninguna otra cosa" (56) en el que fermenta una materialidad trans, drag, impura, móvil y relacional

10 Especialmente interesante resulta que vacas y caballos, protagonistas de una violencia real reduplicada en su correlato simbólico, sean aqui tratados con amor y empatía, incluso aunque sigan cumpliendo las funciones asignadas por la lógica ganadera. 
(Haraway, 2015). Valiéndonos de las descripciones biológicas más recientes, podriamos decir que se despliega aqui una mirada sobre lo existente como un conjunto de sistemas simpoiéticos, que se auto-producen colectivamente, poblados por criaturas multiespecíficas, llamadas holobiontes (Margulis\&Sagan, 2001)11. Los rios son animales, como las lagunas; los yvyra, santidades (178), las vacas, los indios, los cristianos y los caballos, "estructura ósea, mineral, como las piedras" (34). La muchacho rubia será tararira, el gaucho Martín Fierro, china disfrazada de flamenco (157) y le indie Kaukalitrán, tigra. De este modo, el supuesto vacio sobre el que se quiere construir la nación se revela como una aventura vegetal donde la semilla se hincha en la humedad y se abre paso en la negrura esquivando

cuises y vizcachas, se rompe en tallo, en hoja verde, atraviesa la entraña, emerge todavía munida de sus dos cotiledones hasta que logra extraer la fuerza suficiente del sol y del agua como para dejarlos caer y ahí aparece la vaca y se la come a la hierbita esa que le nació al suelo y se reproduce, la vaca, y se multiplica lenta y segura en generaciones que van a parar, casi todos, al degüello, y cae la sangre al suelo de las semillas y los huesos le construyen un esqueleto de delicias para caranchos y lombrices y la carne viaja en los barcos frigoríficos hasta Inglaterra, otra vena, una cruenta y helada, de esa trama que va de todas partes al centro, al corazón voraz del imperio (56-57).

\section{El fortín, crítica de la facultad de vigilar y castigar}

Como una especie de desenvolvimiento hegeliano invertido, en esta novela no es la idea que sale de si a la naturaleza, sino que es la naturaleza (el falso desierto lleno de entidades por el que se desplaza la carreta) la que se enajena en su ingreso al Fortín. El Fortín funciona como el contrapunto negativo de esa primera consolidación de una pequeña comunidad interespecies, que devendrá multiterreinos en el encuentro final con los indios y sus acólitos. Naturaleza y Cultura serán desestabilizados en tanto que opuestos en las dos primeras partes, impidiendo ya "la vuelta", a la una o a la otra ${ }^{12}$. Si en la primera parte la "barbarie" y el "vacio" del desierto fueron transformados por la varita mágica de Cabezón Cámara en nueva vida de amorosa ilustración (la carreta lleva dentro el mundo entero) y en "humus" que alberga materia orgánica en oxidación, en la segunda la "civilización" y el "trabajo" (actividad que en la dialéctica hegeliana lleva a la constitución de una cultura humana) muestran el carácter extractivista, disciplinador (con los gauchos), genocida (con los indios) y demente del proyecto ilustrado empeñado en "conquistarle una tierra a la patria" (105).

"El Fortin" relata la estadia de la carreta y sus acólitos en la estancia modelo de José Hernández, el coronel que hace patria disciplinando gauchos y chinas con sangre y escuela; mejorando sus riquezas a partir del principio capitalista del trabajo en montaje y sosteniendo la soberanía sobre la base de la lógica amigo-enemigo. Se trata de una ingeniosa deconstrucción del proyecto de consolidación nacional argentino y los mitos fundacionales en los que se sostiene, quizás por ello ésta ha sido la cuestión que más ha interesado a la crítica, por la revisión de la relación entre la gauchesca como género literario y la conformación de la identidad nacional.

Sin agotar esa discusión, quisiera dejar señalados algunos elementos importantes para una crítica materialista como la que me he propuesto hacer aquí.

Lo primero que la cercanía de la civilización nos trae es la cruda visión de aquello que queda fuera de ella y la delimitación de la frontera a partir de la cual comienza: a medida que avanza la carreta hacia Las Hortensias encuentra pri-

11 Criaturas multiespecificas (compuestas de células provenientes de distintos tipos taxonómicos) que se relacionan con otras criaturas de características similares, como la Mixotricha paradoxa, esa "paradoja con los pelos mezclados" que vive como simbionte en el interior del tracto digestivo de la termita Mastotermes darwiniensis facilitándole la digestión de la celulosa que compone la madera que come. 12 Con todas las distancias del caso dado que el espíritu según Hegel no ha visitado jamás las Américas, la historia del gaucho Martín Fierro, por su parte, acaso sí podria ser una puesta en obra de una solución dialéctica a la dicotomía sarmientina entre civilización (la ley del Estado) o barbarie (código rural y tradicional): el gaucho esencialmente bueno aunque bárbaro es apresado por los brazos de un Estado civilizador aún injusto del cual se libera transformándose en un matrero (en la La ida), pero vuelve a la sociedad "domesticado" (en La vuelta). Asi parece leerlo Gamerro aunque sin remitirlo a la dialéctica hegeliana (52-53). 
mero seis cadáveres de indios (comedero para seis mil chimangos); luego, una polvareda trae consigo una horda ${ }^{13}$ multiespecie de animales: lombrices, gusanos, cuises, liebres, perdices, ratas, vizcachas, mulitas, peludos, pichis, matacos, choiques, ñandúes, ciervos colorados, pumas y jabalies salvajes (85) que huyen como disparados del lugar donde gauchos esclavizados cavan el límite del fortín, bajo la vigilancia atenta de un milico a caballo. El poder del Estado-Nación en ciernes hace su entrada triunfal, un poder de vida y muerte diferenciador que traza en torno a si el círculo de vidas que importan: exterminio de los indios, disciplinamiento de los gauchos, explotación de animales de granja y plantas cultivables, indiferencia frente a los todos los seres que ni contribuyen ni impiden el proyecto civilizatorio.

Siguiendo los preceptos del incipiente higienismo liberal (que asocia civilización, limpieza y salud) para entrar en la estancia-fortín los humanos de la carreta deben limpiarse, pues el polvo que la propia civilización levanta modificando el terreno es el gran enemigo, como la mugre o la vagancia. Rosa cepilla su uniforme, su montura y su caballo (86), Liz se transforma "como una planta casi seca con la lluvia" luego de un baño y ante los signos de la civilización (88) y la china, convertida recientemente en lady, se transforma en un joven gentleman.

El personaje de Hernández, borracho y charlatán, encarna el poder a la vez político y económico encargado de "hacer la patria" a través de la implantación de una "industria pastoril" (89). Para ello gobierna su tierra con una especie de biopolitica de las pampas que combina el antiguo poder de muerte (hacer morir a los indios) con el poder de vida (hacer vivir a los gauchos reformados, recursos humanos necesarios para garantizar la riqueza de los estancieros: no dejar que "se le muriera ninguno sin razón", se propone Hernández, (112)1) ${ }^{14}$. Poder diferenciador de vida y muerte sostenido en la lógica política del amigo-enemigo: los gauchos necesitan un enemigo para hacerse argentinos, explica, entusiasta del progreso, Hernández a Liz (135).

Un poder que, por lo demás, advierte Cabezón Cámara, no se ejerce sólo sobre la humanidad, pues parte del cálculo también son aquí animales y plantas: como a los gauchos, a las vacas hay que cuidarlas para que cumplan su función, y ser agricultor es "como estar en una guerra" (104). El poder civilizatorio garantiza un lugar jerárquicamente ordenado a cada entidad que exista en la pampa alambrada. Y el principio educador y reformista se aplica a todo lo que la habite. La china narra el experimento civilizatorio sin asumir la excepcionalidad humana, por ello se hace visible en su crónica el extractivismo generalizado en el que se sostiene.

Por ello, tras la lectura de esta novela podría decirse que si el Martín Fierro es la propuesta de Hernández para la solución de la dicotomía sarmientina que no implique la disolución de uno de los polos (gauchos/Estado), es porque la barbarie que alli se considera es sólo un eslabón en la cadena jerárquica que se mantiene intacta hacia abajo, un umbral del círculo inmunológico que determina qué vidas ingresan a la sociedad de iguales y qué cosas son los recursos (humanos o naturales) para sostenerla. Abajo en la cadena, fuera del círculo quedan las chinas, los indios, las vacas, los carpinchos, los árboles, los ríos, etc. La cosmopolítica que abre la China no busca seguir ampliando ese círculo, inestabilizar la dicotomía para conservarla ampliada, sino pensar una política otra, es decir, un vínculo, un lazo, un entramado que sea también un conflicto de todo lo que quedó fuera del establecimiento mismo de la dicotomía legalismo/ilegalismo (que, después de todo, requiere siempre de una ley que le sirva de criterio).

La China presenta todo aquello que queda fuera de la ley para que ésta pueda separar entre legalidad e ilegalidad y aplicarse de forma diferencial, todas las criaturas frente a las que la ley parece indiferente. La china es ella misma una desertora, como su marido, una desertora del hogar, del lugar que le fue asignado en un

13 Uso adrede esta palabra que refiere generalmente a grupos desordenados de personas y no de animales para enfatizar la sutileza de Cabezón Cámara al ubicar su narración fuera del excepcionalismo humano, incluso aunque la narradora pertenezca a esa especie.

14 Una biopolítica que es la continuidad de un sistema en el otro, más acorde a la lectura agambeniana que a la foucaultiana que piensa la disrupción entre uno y otro modelo, digamos (Cfr. Agamben, 1995 y Foucault, 2000). 
sistema de producción y de reproducción que la explotaba sin que recibiera una paga (la familia). Pero al salir de alli no sale en busca de sus derechos, de lograr una ampliación para los derechos universales del hombre que la incluyan por fin. No es suyo el problema del autor del Martín Fierro que exige que se cumpla el principio ilustrado de la igualdad de todos los hombres (que en su caso incluye a los gauchos mas no a los indios, siempre ese principio necesitará un afuera) ante la ley (cfr. Gamerro, 71-80). La solución de Cabezón Cámara al problema del estanciero Hernández es la ilusión de una matria desterritorializada, nómade e imperceptible que logre incluso salvar al pobre Fierro de su destino civilizado.

\section{Tierra Adentro, matria desujetada e imperceptible}

Quisiera, entonces, para cerrar este análisis, presentar algunos aspectos de lo que podría ser ese proyecto político interreinos que se ofrece en la tercera parte.

Nuestros personajes se hartan pronto de "tanta simulación" (129) y traman una huida a todo estruendo que les permita llevarse consigo también una veintena de los gauchos más vaquianos: Cabezón Cámara escenifica un festín orgiástico sin ritualidad como los que los escritores decimonónicos imaginaban entre los malones indios (cfr. Gamerro, 108 y stes.), pero dentro de la estancia, con un Hernández entregado a las delicias culinarias y al ponche preparados por la inglesa. La confusión del día después es el portal que se abre hacia tierra adentro.

Nada más salir de la cueva donde se fabrican los ideales de la nación Argentina, todes, los bueyes ya descansados, las vacas, los terneros, los caballos, la tríada de animales humanos y Estreya, respiran nuevamente, y rien (139). El desierto se ha vuelto ahora materia actuante: se escucha el croar de la tierra mojada de la que brotan hongos (144 y 146), el "agua duplica la felicidad como duplica todo lo que espeja" (147), la pampa se ondula como un lomo de perro desperezándose y las mariposas impulsivas vuelan errantes albergadas en esa masa viva que es el aire (146).
Pero el encuentro con los indios, que no habitan el desierto, sino que son uno con él (152), es quizás el operador que transforma a los elementos (agua, aire, tierra y fuego) en parte de esta comunidad ahora sí interreinos, holoéntica. Una comunidad sin miembros individuales, que es viento (Newen) y deviene agua, pero simula ser monte para protegerse de los paladines del progreso. El lazo que hay se revela como siempre-ya junto, mezclado e impuro, una superficie sin adentros ni afueras, una existencia ni natural ni cultural, que migra imperceptible por el Paraná, "ese animal que gusta vivir en partes" (175). Una organización que cambia de jefes constantemente (152), sin centro (155), sin división del trabajo más que por "la aptitud, el deseo y la necesidad" (156), integrada por indios mezcla de selk'nam, tehuelches y wincas (152) y por extranjeros diversos: las cautivas inglesas que andaban sueltas, los cientíicos alemanes que juntaban huesos de dinosaurios, y hasta por los exiliados de la República Argentina (156) y el propio marida del china con los hijas de ambos. Una nación que se mueve leve como el viento, pues no quiere aplastar lo que pisa (171), que pide perdón a los corderos degollados y los abraza para que mueran amados (165), que no vota y que, a falta de armas, decide vivir en casas que se sostienen en el agua (wampos-rukas), subir las vacas a los árboles con la crecida, regalándoles una perspectiva aérea, y vivir contemplando los yvyra, haciéndose sabios a partir de la experimentación con las plantas. Un comunismo que se busca vegetal, podriamos decir, descentrado y sin identidades presupuestas, suma de diferencias (Marder, 2014, 7) pero indiferente a todo privilegio soberano y que comunica lo biótico y lo abiótico en una sympoiesis que ha hecho del desierto el paraiso. No una internacional, una interreinos (Billi, 2018) que hay que ver, pero que no veremos:

Hay que vernos, pero no nos van a ver. Sabemos irnos como si nos tragara la nada: imagínense un pueblo que se esfuma, un pueblo del que pueden ver los colores y las casas y los perros y los vestidos y las vacas y los caballos y se va desvaneciendo como un fantasma: pierden definición sus contornos, brillos sus colores, se funde todo con la nube blanca. Así viajamos" (185). 
No es que se diluyan aquí con una salida más o menos ética los problemas de la "constitución de la patria": por un lado, no se trata del retorno a una Naturaleza pristina anterior a la llegada del proyecto civilizatorio, pues la naturaleza es aqui queer, y por el otro, tampoco se trata de un paso hacia la "intimidad" de una comunidad de amigos que renuncian a la vida en sociedad. Es la comunidad de los que no tienen comunidad porque quedan excluidos de todo concepto de comunidad: perro, china, extranjera, caballos, gaucho perdido, indios, vacas, río, viento, etc., etc., etc.

El reencuentro con Fierro en esta parte, quien luego de perdido su gran amor Cruz, vive entre los indios con sus dos hijos, le proporciona una vía de escape a "La vuelta" a la civilización que le habia pergeñado Hernández en su poema. Al revés que el Fausto de Goethe salvado del extravio por el eterno-femenino que lo empuja hacia arriba, Fierro es salvado por una muchacha indecible, indeterminada que lo devuelve a lo bajo, a la materia mezclada, al compost que somos y le comparte su nación errante.

Como en El entenado de Juan José Saer, que a juicio de Gamerro $(2015,132)$ es la novela que redime el poema estética y moralmente horrible que es La cautiva de Esteban Echeverria ${ }^{15}$, en el final de la China se palpa "la pulpa brumosa de lo indistinto", de "la chicana de una criatura demasiado mimada en un hogar material hecho de necesidad y de inocencia" (Saer, 2004, 188189). No obstante, hay aqui un sutil corrimiento respecto de la tristeza metafísica que embarga el final del relato del único sobreviviente del canibalismo colastiné ejercido sobre el descubridor del Río de la Plata y sus soldados. Porque las oposiciones metafísicas que Saer construye, donde indio y blanco quedan ambos de un mismo lado, se disuelven en la China: lo inerte, lo viscoso y la negrura ya no son la Naturaleza contra la que lucha el humano para poder erigirse. La comunidad de la china es la indistinción, que no es homogeneización juridica, entre real/irreal, nombrable/innombrable, humano/inhumano y cosmos/caos. Las lógicas de existencia del pueblo interreinos ya no se presentan en pares de opuestos, pues está conformado por los retazos irrecuperables que sobran de su recorte.

\section{Bibliografía:}

ADORNO, Theodor, W. Terminología filosófica, T. II. Trad. R. Sánchez Ortíz de Urbina. Madrid: Taurus, 1977.

AGAMBEN, Giorgio. Homo sacer l: El poder soberano y la nuda vida. trad. A. G. Cuspinera. Valencia: Pre-textos, 1995:

AGAMBEN, Giorgio. Idea della prosa. Macerata: Quodlibet, 2002

AGAMBEN, Giorgio. Kommerell, o del gesto. En: KOMMERELL, Max. Il poeta e l'indecible. Trad. it., G. Giometti. Genova: Casa Editrice Marietti, 1991. p. vii-xv.

AGAMBEN, Giorgio. La ragazza indicibile. Mito e mistero di Kore, Milano, Electa, 2010.

AGAMBEN, Giorgio. Notas sobre el gesto. Medios sin fin. Notas sobre la politica, trad. A. G. Cuspinera. Valencia: Pre-textos, 2001. p. 47-55.

AGAMBEN, Giorgio. Parodia. Profanazioni. Roma: Nottetempo, 2005. p. 39-56.

BILLI, Noelia. Política y ontología. De La Internacional a La Interreinos. Pensamiento de los confines, Buenos Aires, n. 31, 2018.

BRAIDOTTI, Rosi. Four Theses on Posthuman Feminism. En: GRUSIN, Richard (ed.). Anthropocene Feminism. Minneapolis/London: University of Minnesota Press, 2017. p. 21-47.

BRAIDOTTI, Rosi. Lo Posthumano. trad. J. C Gentile Vitale. Barcelona: Gedisa, 2015.

CABEZÓN CÁMARA, Gabriela. Las aventuras de la China Iron. Buenos Aires: Literatura Random House, 2018.

DAVIS, Heather; TURPIN, Etienne (ed.). Art \& Death: Lives Between the Fifth Assessment \& the Sixth Extinction. Art in the Anthropocene. Encounters Among Aesthetics, Politics, Environments and Epistemologies. London: Open Humanities Press, 2015. https://doi.org/10.26530/ OAPEN_560010.

FEDER, Helena. Ecocriticism and the Idea of Culture: Biology and the Bildungsroman. Abingdon: Routledge, 2013.

FISCHER, Mark. Realismo capitalista. ¿No hay salida? Trad. C. Iglesias. Buenos Aires: La caja negra, 2016.

15 Baso mi lectura de la China en este punto sobre la genial lectura en contrapunto que propone Gamerro entre La cautiva, el poema que fija los modos arquetípicos de imaginación paranoica del malón indígena, de Esteban Echeverría y El entenado (Capítulo: La orgía indigena de Echeverria a Saer). Dice Gamerro: "El entenado nos retrotrae a los primeros encuentros del indio y el blanco, en tiempos del descubrimiento y la conquista, y está inspirada en la historia de Francisco del Puerto, único sobreviviente de la masacre en que murió Juan Díaz de Solís, descubridor del Río de la Plata, y del festín que la habría sucedido" (Gamerro, 2015,118-119). 
FOUCAULT, Michel. Clase del 17 de marzo de 1976. En Defender la sociedad, trad. H. Pons. Buenos Aires: Fondo de Cultura Económica, 2000

FOUCAULT, Michel. ¿Qué es la ilustración?, trad. S. Mattoni. Córdoba: Alción, 1996.

GAMERRO, Carlos. Facundo o Martín Fierro: Los libros que inventaron la Argentina. Buenos Aires: Sudamericana, 2015.

GRUSIN, Richard. Introduction: Anthropocene Feminismo, An Experiment in Collaborative Theorizing. In: GRUSIN, Richard (ed.). Anthropocene Feminism. Minneapolis/London: University of Minnesota Press, 2017. p. vii-xix.

HARAWAY, Donna. Anthropocene, Capitalocene, Plantationocene, Chthulucene: Making Kin. Environmental Humanities, Durham, v. 6, p. 159-165, 2015. https://doi. org/10.1215/22011919-3615934.

HARAWAY, Donna. Symbiogenesis, Sympoiesis, and Art Science Activisms for Staying with the Trouble. En: TISNG, Anna et al. Arts of Living on a Damaged Planet. Minneapolis: University of Minnesota Press, 2017. p. 25- 50.

HARAWAY, Donna. Seguir con el problema: General parentesco en el Chthuluceno. Trad. H Torres. Bilbao: Consonni, 2019.

LATOUR, Bruno. Cara a cara con el planeta. una nueva mirada sobre el cambio climático alejada de las posiciones apocalipticas. Trad. A. Dilon. Buenos Aires: Siglo XXI, 2017.

LATOUR, Bruno. Imaginer les gestes-barrières contre le retour à la production d'avant crise.

AOC Analyse Opinion Critique. Paris: 29 abr. 2020. Disponible en: https://aoc.media/opinion/2020/03/29/ imaginer-les-gestes-barrieres-contre-le-retour-a-la-production-davant-crise. Acceso en: 30 abr. 2020.

LUDMER, Josefina. El género gauchesco: Un tratado sobre la patria. Buenos Aires: Eterna Cadencia, 2012.

MARDER, Micheal. For a Phitocentrism to come. Enviromental Philosophy, [s. l.], n. 11, v. 2, 2014. https://doi. org/10.5840/envirophil20145110.

MARGULIS, Lynn, SAGAN, Dorion. The Beast with Five Genomes. Natural History, [s. l.], v. 110, n. 5, junio 2001. Disponible en: http://www.naturalhistorymag.com/htmlsite/0601/0601_feature.html. Acceso en: 30 abr. 2020.

MORETTI, Franco. The Way of the World. The Bildungsroman in European Culture. New York: Verso, 2000.

RODRiGUEZ, Fermín. Un desierto para la nación. La escritura del vacio. Buenos Aires: Eterna Cadencia, 2010.

ROSSINI, Manuela. To the Dogs: Companion speciesism and the new feminist materialism. Kritikos, an international and interdisciplinary journal of postmodern cultural sound, text and image, [s. l.], v. 3, Sept. 2006. Disponible en: http://intertheory.org/rossini. Acceso en: 30 abr. 2020.

SAER, Juan José. El entenado. Buenos Aires: Seix Barral, 2004 .
STENGERS, Isabelle. En tiempos de catástrofes: cómo resistir a la barbarie que viene. Trad. V. Gondstein. Buenos Aires: Futuro Anterior, 2017.

\section{Paula Fleisner}

Profesora y Doctora en Filosofía por la Universidad de Buenos Aires. Docente en Estética en la carrera de Filosofia de la UBA. Investigadora adjunta de CONICET.

\section{Dirección}

Paula Fleisner

Instituto de Filosofía, Universidade de Buenos Aires

Puan 480, C1420

Ciudad Autónoma de Buenos Aires, CABA, Argentina. 